\title{
Rasmussen's Encephalitis: A Case Report
}

Suneel Kumar', Saeed Ahmed ${ }^{2 *}$, Shahana Ayub ${ }^{3}$, Fatima Bilal Motiwala1', Naveed Ahmed ${ }^{4}$, Vikash' and Rizwan Ahmed ${ }^{3}$

${ }^{1}$ Department of Neurology, Jinnah Post Graduate Medical Centre, Rafiquee Shaheed Road, Karachi, Pakistan

${ }^{2}$ Department of Psychiatry, NYULMC NYU School of Medicine, NY, USA

${ }^{3}$ Aga Khan University Hospital, Karachi, Pakistan

${ }^{4}$ Department of Radiology, Jinnah Post Graduate Medical Centre, Rafiquee Shaheed Road, Karachi, Pakistan

\begin{abstract}
We report a case of Rasmussen's Encephalitis. It is a rare, chronic inflammatory neurological disease of unknown origin that usually affects only one hemisphere of the brain. It is common in children under the age of 10 with average age at disease onset around 6 years but uncommon in adults, adult variant that accounts for about $10 \%$ of the cases only. Rasmussen's Encephalitis is characterized by intractable severe seizures, loss of motor skills and speech, paralysis on one side of the body (dysfunctions associated with the affected hemisphere). Our case is a 21 years old female, presented to emergency department JMPC Karachi with complaint of intractable severe seizures, progressive hemiparesis and deteriorated cognition followed by an episode of encephalitis. Her course of illness was focal seizures and right-sided weakness (hemiparesis) for 5 months. In addition to classical clinical presentation of Rasmussen's Encephalitis, MRI Brain showed hemispheric atrophy of one cerebral hemisphere and old gliotic changes that further supports diagnosis of Rasmussen's Encephalitis.
\end{abstract}

Abbreviations: CT: Computed Tomography; MRI: Magnetic Resonance Imaging; RE: Rasmussen's Encephalitis; HT: Hemispherectomy

\section{Introduction}

Rasmussen's encephalitis is a chronic inflammatory disease of unknown origin, brain inflammation resulting in unilateral brain atrophy that was first described by Rasmussen et al. in 1958 [1]. Clinically this disease is characterized by drug-resistant focal seizures, progressive weakness, worsening of motor and cognitive functions $[1,2]$. It is common in children under the age of 10 with average age at disease onset around 6 years [3] but uncommon in adults, adult variants account for around $10 \%$ of the total cases [4].

Various etiological hypotheses have been postulated about Rasmussen's encephalitis, some researchers revealed cell-mediated immunity relates the pathogenesis of $\mathrm{RE}$, more precisely $\mathrm{T}$-cell immunoreaction against neurons and astrocytes $[5,6]$. Cell medicated hypothesis is further supported by a recent study by Granata et al. that suggests that cytotoxic $\mathrm{T}$ cells may be directed against a viral protein presents in both neurons and astrocytes [7]. But there is another school of thought which supports autoimmune pathology [8]. In 1994, Rogers et al. found role of antibodies against glutamate receptor (GluR3), other triggers have also shown to be associated with etiology, like herpes simplex virus and cytomegalovirus found [8].

Diagnosis is based on clinical, imaging, and histopathological findings, focal seizures and unilateral cortical deficit on examination are important clues to help in diagnosis. However, imaging studies could be challenging for diagnosis in initial stages of Rasmussen's encephalitis [9].

There are no biomarkers for RE to diagnose RE, the presence of anti-GluR3 is not considered specific for the diagnosis, since it does not discriminate between $\mathrm{RE}$ and other non-inflammatory epilepsies [10]. However histopathology of brain by open biopsy provides an important finding to diagnose RE. Biopsy for the diagnosis of RE shows multifocal changes of the $\mathrm{T}$ cell dominated encephalitis with activated microglia and reactive gliosis [11], but some believe that CSF standard tests are not suitable to confirm or to exclude the diagnosis of RE [2].
Treatment strategies vary among different patients at different stages, treatment options are selected according to need of patient. There is insufficient evidence and data for most effective treatment of RE [12], In medical treatment corticosteroids are often used and shown robust and effective response [13], similarly intravenous immunoglobulin (IVIg) and Plasmapheresis (PEX) have been used and proven to be effective for short term response but inefficient to achieve long terms results [14]. Whilst comparing to medical treatment options, surgically hemispherectomy is generally considered more useful and widely accepted treatment option because it is highly effective to eliminate seizures and one of modern treatment option for $\mathrm{RE}$ [12]. Surgical approach is tailored to remove affected hemisphere by hemispherotomy, and the only potential treatment that able to control seizures and prevent from further mental deterioration in these patients [15].

\section{Case Presentation}

21 years unmarried female known case of focal epilepsy came to emergency department of JMPC Karachi, patient presented with uncontrolled intractable seizures and hemiparesis. On arrival she was give diazepam and phenytoin infusion, same time investigated with CT scan of brain (stat), after acute management, patient was transferred on floor in neurology ward. After moving to ward she was started on phenytoin and clonazepam orally but fits did not seize and became worsened and uncontrollable. Soon after this condition levetiracetam infusion was started promptly, After 72 hours of treatment, patient continued to develop seizures, besides seizures her right-sided weakness persisted, progressed and became worsen. During these episodes of fits,

*Corresponding author: Saeed Ahmed, Department of Psychiatry, NYULMC NYU School of Medicine, NY, USA, Tel: 646-754-4858; E-mail: ahmedsaeedmd@gmail.com

Received December 09, 2013; Accepted January 06, 2014; Published January 09, 2014

Citation: Kumar S, Ahmed S, Ayub S, Motiwala FB, Ahmed N, et al (2014) Rasmussen's Encephalitis: A Case Report. J Neurol Disord 2: 145 doi:10.4172/2329-6895.1000145

Copyright: ( 2014 Kumar S, et al. This is an open-access article distributed under the terms of the Creative Commons Attribution License, which permits unrestricted use, distribution, and reproduction in any medium, provided the original author and source are credited. 
Citation: Kumar S, Ahmed S, Ayub S, Motiwala FB, Ahmed N, et al. (2014) Rasmussen's Encephalitis: A Case Report. J Neurol Disord 2: 145. doi:10.4172/2329-6895.1000145

Page 2 of 2

blood sample was collected for baseline investigations (complete blood picture, ESR, blood culture \& sensitivity, comprehensive metabolic profile, thyroid function test, blood Sugar, urine toxicology, blood toxicology, ANA profile). Laboratory tests were reported soon after ordering and results shown within normal limits. Lumber puncture and MRI Brain with contrast were also performed. The CSF report showed normal glucose, increased protein, increased lymphocytes, and also (PCR) for Herpes Simplex Virus appeared to be negative. The CT scan brain shown atrophy of left hemisphere. The MRI showed high signal intensity area is seen in bilateral temporal lobes and right partial cortex with adjacent effacement of cortical sulci and also asymmetry between two cerebral hemisphere with atrophy of one cerebral hemisphere represent old gliotic changes. In the suspicion of Herpes Simplex Virus Encephalitis empirical antiviral treatment was given but patient continued to have seizures without any clinical stability, and focal seizures labelled as "epilepsia partialis continua".

\section{Discussion}

Typically management of Rasmussen's encephalitis is tailored to control intractable seizures and alter disease progression with the aid of various treatment strategies, for example, antiepileptic drugs, immune suppressants, immune modulators and Immunoglobulin, plasmapheresis and surgical treatment like Hemispherotomy. Our patient presented with severe seizures and one-sided weakness, she was managed with conventional antiepileptic drugs, diazepam and phenytoin. levetiracetam, clonazepam, These antiepileptic drugs were used at different times while on admission and transferring to floor, AED were switched to one on other for next 72 hours, but regimen remained unsuccessful, IV Immunoglobulin or Plasmapheris were not applied due to unavailability of resources, similarly Hemispherectomy was not offered due to unavailability of specialized neurosurgeon for required procedure, evidence and data (No Clinical Trial) have shown fair results to abort uncontrollable seizures with Hemispherectomy $[2,12,15]$. Our patient was qualified for surgical procedure due to weakness in arm but due to limited sources, generally accepted Hemispherectomy was not performed. So the patient was conservatively managed during the hospital stay and referred to another tertiary care hospital for surgery. We tracked our patient to the referred hospital; patient had refused to sign high-risk consent for surgery and discharged on antiepileptic medicine.

\section{Conclusion}

Our patient presented with the clinical history of a Rasmussen's encephalitis. Though we diagnosed our patient on basis of clinical judgment and imaging studies, we tried available conventional therapies to treat our patient at out best.

\section{Authors' Contributions}

SK developed the idea for the case report and headed the study, and then he revised the draft of the case report, and provided a critical review of the study. SA and FM helped to write case report. SA, RA, FM helped to write discussion and Case presentation section. SA and SK worked on endnote to fix references. All authors read and approved the final manuscript.

\section{References}

1. Rasmussen T, Olszewski J, Lloydsmith D (1958) Focal seizures due to chronic localized encephalitis. Neurology 8: 435-445.

2. Bien CG, Granata T, Antozzi C, Cross JH, Dulac O, et al. (2005) Pathogenesis, diagnosis and treatment of Rasmussen encephalitis: a European consensus statement. Brain 128: 454-471.

3. Oguni H, Andermann F, Rasmussen T (1991) The natural history of the syndrome of chronic encephalitis and epilepsy: a study of the MNI series of forty-eight cases. Chronic encephalitis and epilepsy Rasmussen's syndrome Boston: Butterworth-Heinemann: 7-35.

4. Hart YM, Cortez M, Andermann F, Hwang P, Fish DR, et al. (1994) Medica treatment of Rasmussen's syndrome (chronic encephalitis and epilepsy): effect of high-dose steroids or immunoglobulins in 19 patients. Neurology 44: 10301036.

5. Bauer J, Elger CE, Hans VH, Schramm J, Urbach H, et al. (2007) Astrocytes are a specific immunological target in Rasmussen's encephalitis. Ann Neurol 62: $67-80$.

6. Schwab N, Bien CG, Waschbisch A, Becker A, Vince GH, et al. (2009) CD8+ T-cell clones dominate brain infiltrates in Rasmussen encephalitis and persist in the periphery. Brain 132: 1236-1246.

7. Granata T, Cross H, Theodore W, Avanzini G (2011) Immune-mediated epilepsies. Epilepsia 52 Suppl 3: 5-11.

8. Rogers SW, Andrews PI, Gahring LC, Whisenand T, Cauley K, et al. (1994) Autoantibodies to glutamate receptor GluR3 in Rasmussen's encephalitis. Science 265: 648-651.

9. Granata T, Gobbi G, Spreafico R, Vigevano F, Capovilla G, et al. (2003) Rasmussen's encephalitis: early characteristics allow diagnosis. Neurology 60 : 422-425.

10. Mantegazza R, Bernasconi P, Baggi F, Spreafico R, Ragona F, et al (2002) Antibodies against GluR3 peptides are not specific for Rasmussen's encephalitis but are also present in epilepsy patients with severe, early onset disease and intractable seizures. J Neuroimmunol 131: 179-185.

11. Pardo CA, Vining EP, Guo L, Skolasky RL, Carson BS, et al. (2004) The pathology of Rasmussen syndrome: stages of cortical involvement and neuropathological studies in 45 hemispherectomies. Epilepsia 45: 516-526.

12. Bien CG, Schramm J (2009) Treatment of Rasmussen encephalitis half a century after its initial description: promising prospects and a dilemma. Epilepsy Res 86: 101-112.

13. Bahi-Buisson N, Villanueva V, Bulteau C, Delalande O, Dulac O, et al. (2007) Long term response to steroid therapy in Rasmussen encephalitis. Seizure 16: 485-492.

14. Granata T, Fusco L, Gobbi G, Freri E, Ragona F, et al. (2003) Experience with immunomodulatory treatments in Rasmussen's encephalitis. Neurology 61: $1807-1810$.

15. Marras CE, Granata T, Franzini A, Freri E, Villani F, et al. (2010) Hemispherotomy and functional hemispherectomy: indications and outcome. Epilepsy Res 89: 104-112. 